\title{
BMJ Open Effects of the COVID-19 pandemic on the sexual and mental health of adolescent and adult men who have sex with men and transgender women participating in two PrEP cohort studies in Brazil: COBra study protocol
}

\author{
Dulce Ferraz (1) , ${ }^{1,2}$ Inês Dourado, ${ }^{3}$ Eliana Miura Zucchi, ${ }^{4}$ Xavier Mabire (D) , \\ Laio Magno (1) , ${ }^{5}$ Alexandre D Grangeiro, ${ }^{6}$ Márcia Thereza Couto, ${ }^{6}$ \\ Laura Ferguson, ${ }^{7}$ Mateus Westin, ${ }^{8}$ Lorruan Alves dos Santos, ${ }^{6}$ Marie Préau ${ }^{2}$
}

To cite: Ferraz D, Dourado I, Zucchi EM, et al. Effects of the COVID-19 pandemic on the sexual and mental health of adolescent and adult men who have sex with men and transgender women participating in two PrEP cohort studies in Brazil: $\mathrm{COBra}$ study protocol. BMJ Open 2021;11:e045258. doi:10.1136/ bmjopen-2020-045258

- Prepublication history and additional material for this paper is available online. To view these files, please visit the journal online (http://dx.doi.org/10. 1136/bmjopen-2020-045258).

Received 27 September 2020 Revised 15 March 2021 Accepted 16 March 2021

Check for updates

(C) Author(s) (or their employer(s)) 2021. Re-use permitted under CC BY-NC. No commercial re-use. See rights and permissions. Published by BMJ.

For numbered affiliations see end of article.

Correspondence to

Dr Dulce Ferraz;

dulcefer@gmail.com

\section{ABSTRACT}

Introduction The COVID-19 pandemic and its control measures have impacted health and healthcare provision in various levels. Physical distancing measures, for instance, may affect sexual health, impacting access to HIV prevention supplies and changing sexual behaviour, as well as mental health, increasing feelings of unsafety and weakening community support ties. These effects can be worsened among socially marginalised groups, such as men who have sex with men (MSM) and transgender women (TGW). Brazil is among the countries most affected by COVID-19 in the world, where control measures have been inconsistently implemented. We aim to investigate the effects of the COVID-19 pandemic on the sexual and mental health of adolescent and adult MSM and TGW in Brazil.

Methods Convergent mixed-method prospective cohort study, nested in two ongoing HIV pre-exposure prophylaxis (PrEP) cohorts in Brazil, named PrEP1519 and Combina. Participants will be invited to answer, at baseline and after 6 months, a questionnaire about the effects of the COVID-19 pandemic on sexual behaviour, HIV prevention and mental health. Data on HIV infection and sexually transmitted infections (STI) will be collected as part of routine follow-up from the cohorts. Main outcome measures (HIV infection, STI and depression symptoms) will be observed within 12 months after baseline. Sample size is estimated at 426 participants. Complementarily, 50 participants will be invited to in-depth interviews through video calls or interactive voice response, and 20 will be invited to chronicle their lives during the pandemic through digital diaries. Triangulation will be done across qualitative methods and with the quantitative data.

Ethics and dissemination The study was approved by Research Ethics Committees from the Brazilian Universities coordinating the study. Findings will be published in scientific journals and presented at meetings. Informative flyers will be elaborated to communicate study findings to participants and key stakeholders.
Strengths and limitations of this study

The study builds on two ongoing pre-exposure prophylaxis cohorts in Brazil, which allows exploring the effects of the COVID-19 pandemic on the sexual and mental health of a large sample of youth and adults men who have sex with men and transgender women (TGW) as the pandemic unfolds.

- Mixed methods will allow a comprehensive approach of how the COVID-19 pandemic affects the web of causation of HIV infection among these groups.

- The study uses innovative data collection techniques, such as web-based diaries and reports with photographs.

- Remote data collection implies limits, such as not being as aware of participants' facial expressions and body language nor to reach individuals with poor or no access to the internet.

- The number of TGW in the cohorts is reduced, which may hinder statistical analysis for this population, depending on their rates of adherence to the present study.

\section{INTRODUCTION}

\section{COVID-19 in Brazil}

The COVID-19 pandemic is currently a major global health issue. ${ }^{1}$ Besides being a health emergency in itself, the pandemic may intensify other health issues and result in a significant setback for the control of other infectious diseases. ${ }^{2}$ Health systems placed under considerable strain, ${ }^{3}$ along with physical distancing measures ${ }^{4}$ can hamper access to healthcare and lead to social isolation, negatively impacting people's physical and mental health. ${ }^{5}$ 
In Brazil, the first case of COVID-19 was officially identified on 25 February 2020. ${ }^{6}$ On 20 March, the Brazilian Ministry of Health $(\mathrm{MoH})$ declared the existence of community transmission nationwide. ${ }^{7}$ By 26 January, Brazil had recorded 8.878.795 cases and 217.831deaths, with a fatality rate of $2.45 \%,{ }^{8}$ being currently the country with the third highest number of cases and the second in number of deaths globally. ${ }^{9}$

This epidemiological situation is due to a range of factors that may be hampering people's ability to comply with control measures, especially with physical distancing, that is, the practice of staying home as much as possible to prevent the spread of SARS-CoV-2 and of maintaining physical space (at least $6 \mathrm{ft}$ ) from others in public areas.

One important factor is the absence of a nationally articulated response to COVID-19. While the country's President has denied the seriousness of the disease, local governments have been implementing control measures not always fully guided by the local epidemiological situation. ${ }^{10}{ }^{11}$ Contradictions and disregard of scientific evidence may be affecting people's perception of the disease and their trust in the information disseminated by authorities, which are key elements to the adoption of protective behaviours. ${ }^{12}$ Also, insufficient and belated implementation of emergency social protection measures ${ }^{11}$ may be hampering people's ability to comply to physical distancing measures, considering that the country has 66 million people living in poverty and only $40 \%$ are formally employed ${ }^{13}$

\section{Potential effects of the COVID-19 outbreak on sexual and mental health}

Disease outbreaks can impact sexual health and rights at individual, systemic and societal levels, heightening vulnerabilities of individuals, with immediate and lasting negative consequences for their health, ${ }^{3}$ as seen in previous pandemics. ${ }^{14} 15$ Thus, attention has been called to the potentially detrimental effects of the COVID-19 pandemic on HIV. ${ }^{216}$ Prioritising the response to COVID-19 could reduce the availability of HIV-related healthcare delivery, entailing a shortage of supplies and diversion of healthcare providers and financial resources. ${ }^{3718}$ Interruptions in HIV treatment and delayed antiretroviral treatment (ART) initiation, along with late diagnosis and limited access to prevention services could contribute to a significant increase in HIV incidence and AIDS-related deaths during and after the COVID-19 crisis. ${ }^{2} 1920$

In Brazil, the provision of minimum healthcare services during the pandemic has been recommended by the $\mathrm{MoH}$, including HIV testing, treatment and prevention services. ${ }^{21}$ However, the urgency to respond to COVID19-related demands have limited service delivery ${ }^{22} 23$ and required adaptations to respect physical distancing measures, often using telehealth. ${ }^{24}{ }^{25}$ Besides, even if services are available, physical distancing recommendations can make people avoid seeking healthcare during the pandemic. ${ }^{317}$
The impact of the COVID-19 pandemic on the HIV epidemic may be more severe among groups that are marginalised and disproportionally affected by HIV, such as transgender women (TGW) and men who have sex with men (MSM) in Brazil. ${ }^{26}{ }^{27}$ MSM and TGW may be less willing to disclose sexual health needs during the pandemic to avoid disclosing their sexual orientation and gender identity within the household. ${ }^{28}$ Studies $^{29}$ have observed an increased difficulty among MSM and TGW in accessing HIV prevention services during the pandemic, disproportionately affecting young people. ${ }^{30}$ In Brazil, barriers to picking up pre-exposure prophylaxis (PrEP) refills at health services were the main reason for adult MSM and TGW stopping PrEP during the pandemic. ${ }^{31}$

The COVID-19 pandemic may also impact HIV spread by affecting sexual behaviours. Studies indicate a decrease of casual sex since the pandemic outbreak, ${ }^{18} 3132$ which among youth is associated with increased family supervision and less personal freedom. ${ }^{18}$ A study in Australia ${ }^{33}$ found that reducing casual sex was the main reason to stop taking PrEP; similarly, in Brazil sexual abstinence was among the main reasons to PrEP interruption among MSM and TGW. ${ }^{31}$

The COVID-19 pandemic may also lead to negative mental health outcomes. Physical distancing measures can lead to social isolation, which is associated with anxiety, depression, post-traumatic stress disorder and stigma, both at immediate and long terms. ${ }^{44}{ }^{35}$ In Great Britain, the proportion of adults reporting experiencing some form of depression almost doubled during the implementation of these measures, as compared with the period immediately before it. ${ }^{36}$ In the USA, anxiety disorder and depressive disorder increased considerably between April and June 2020, compared with the same period in 2019, being significantly more common in persons aged $18-24$ years. ${ }^{37}$

Moreover, the pandemic can hamper individuals' and communities' self-care, that is, their ability to take an active role in protecting their own well-being, promoting and maintaining health, as well as preventing disease and coping with illness and disability. ${ }^{38}$ Physical, psychological, spiritual and community support are dimensions of self-care that interrelate and correlate to mental health ${ }^{38}$ and that can be impaired by the pandemic. Among MSM and TGW, in particular, physical distancing measures may contribute to psychological suffering by disrupting everyday community ties and social support ${ }^{39}$ and may increase their exposure to discrimination and violence in the household, especially among youth ${ }^{40} 41$

\section{STUDY AIMS AND HYPOTHESES}

This study aims to investigate the effects of the COVID-19 pandemic on the sexual and mental health of adolescent and adult MSM and TGW participating in two HIV PrEP cohorts in Brazil, with an emphasis on HIV and STI infection.

Secondary aims are to investigate: 
- The social representations ${ }^{42-46}$ of the COVID-19 pandemic and the public understanding of its control measures among MSM and TGW.

- The effects of the COVID-19 pandemic on prevention and on HIV and STI incidence among these groups.

- How MSM and TGW manage self-care during physical distancing measures.

- The prevalence of symptoms of depression among MSM and TGW during physical distancing measures. Our hypotheses are that:

- The COVID-19 pandemic will negatively affect the sexual and mental health of MSM and TGW, with adolescents being more severely affected than adults.

- Public understanding of the scientific evidence of COVID-19 will be affected by the conflicting public messages disseminated in Brazil.

- Social representations of health and disease will be marked by the severity of the COVID-19 pandemic.

- The COVID-19 pandemic may increase the vulnerability of sexual minorities, causing obstacles to accessing healthcare and resulting in increased risk of HIV and STI infection.

- Stressor factors, such as discrimination and violence, are likely to increase during physical distancing measures among MSM and TGW living in hostile family environments.

\section{METHODS}

The study will take place in Brazil from June 2020 to December 2021. It adopts a mixed-method, ${ }^{47}$ multidisciplinary approach, combining epidemiology, social psychology and medical anthropology.

The study is nested within two existing PrEP cohorts, named PrEP1519 and Combina. PrEP1519 is a demonstration study that aims to evaluate the effectiveness of PrEP use among adolescent MSM and TGW aged 15-19, in three Brazilian cities: Belo Horizonte, Salvador, and São Paulo. ${ }^{25}$ Combina is a demonstration study that analyses the effectiveness of PrEP among participants aged 16 years and older. It takes place in six public healthcare services from five Brazilian cities-São Paulo, Ribeirão Preto, Fortaleza, Curitiba and Porto Alegre. ${ }^{48}$
Table 1 shows the estimated HIV prevalence among MSM in these cities in $2016^{27}$ and the COVID-19 cases and deaths recorded until 26 January $2020{ }^{8}$

\section{Theoretical approaches}

Human rights provide an overarching framework for this study that has informed study tools and methods. Recognising the interdependence of all rights, we afford particular attention to the right to health (including the availability, accessibility, acceptability and quality of health services), privacy and confidentiality, equality and non-discrimination and governmental accountability. ${ }^{49}$ Aligned with this framework, the concept of vulnerability ${ }^{51}$ guided the structuring of the research axes. We considered its three dimensions: structural (eg, stigma, violence, living conditions); programmatic (eg, availability of and access to healthcare); and interpersonal (eg, sexual behaviours, risk perception).

Our theoretical approach is also inspired by the theory of social representations. ${ }^{42}{ }^{43}$ Social representations are defined as a form of common-sense knowledge, with a practical orientation, ${ }^{44} 45$ that influence people's conducts. ${ }^{4652}$ People tend to mobilise social representations in contexts of uncertainty to give sense to what is happening and thus adapt their behaviours..$^{53-55}$

Minority stress models ${ }^{56-58}$ will also be applied in the analysis to highlight how different stress factors may affect health among youth and adult MSM and TGW during the pandemic.

\section{Study population}

The study population consists of MSM and TGW participating in PrEP1519 (aged 15-19 years) and Combina (age $\geq 16$ years). The common inclusion criteria for both cohorts are:

- Having a history of recent risk exposure (condomless sex, history of STI infection, use of PEP) or vulnerability to HIV (eg, drug use, sex work or unstable housing).

- Testing negative for HIV at enrollment visit.

- Accepting to participate in the study.

Table 1 COVID-19 cases and deaths in the general population and estimated HIV prevalence among MSM in the COBra (COVID outbreak in Brazil) study sites

\begin{tabular}{lccc}
\hline City & COVID-19 cases & COVID-19-related deaths & HIV prevalence estimate, \% \\
\hline São Paulo & 454900 & 17004 & 24.4 \\
Salvador & 123261 & 3340 & 8.6 \\
Fortaleza & 93897 & 4295 & 10.0 \\
Belo Horizonte & 82714 & 2182 & 14.5 \\
Curitiba & 76729 & 2167 & 20.2 \\
Porto Alegre & 78790 & 2075 & 10.5 \\
Ribeirão Preto & 34017 & 1041 & Data not available \\
\hline
\end{tabular}

MSM, men who have sex with men. 


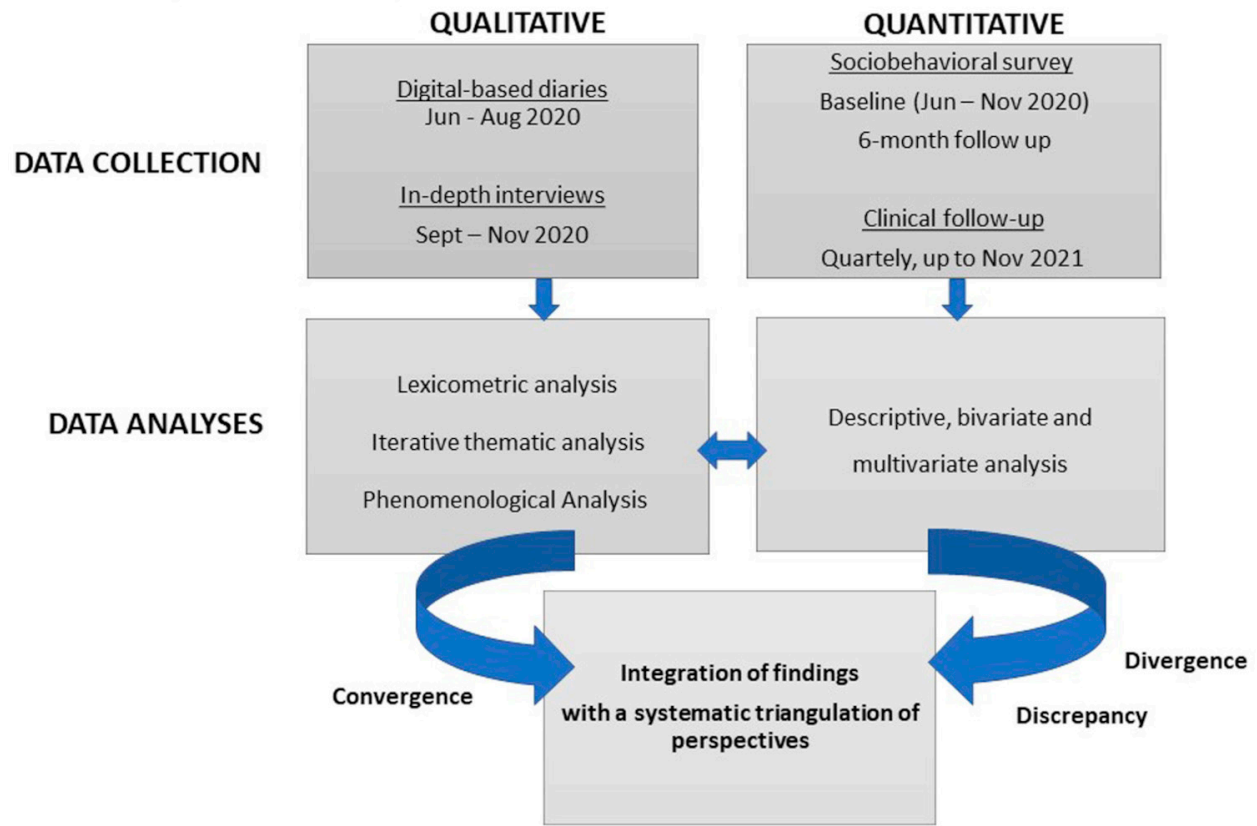

Figure 1 Convergent mixed-methods design: stages and procedures for quantitative and qualitative data collection and analysis at COBra (COVID Outbreak in Brazil) Study.

In the two cohorts, follow-up procedures include quarterly clinical evaluations, counselling and HIV and STI testing. During the physical distancing period, the majority of these consultations and procedures have been done through telehealth, using videoconference, texting and mailing of PrEP pills and HIV self-tests (HIVST) to participants. $^{25}$

\section{Study design}

This is a convergent mixed-methods prospective cohort, with independent and concurrent quantitative and qualitative data collection and analysis, and triangulation of findings.

Since part of the data will be collected during COVID-19 physical distancing measures, we will prioritise remote data collection.

Figure 1 provides an overview of data collection, analysis and integration of methods.

\section{Quantitative design}

Procedures

All participants enrolled in PrEP1519 and Combina, in all the sites, will be invited by phone calls or text messages to respond to an online questionnaire on their experiences with the pandemic. The baseline questionnaire will be applied during the physical distance measures (between June and November 2020) and repeated after 6 months.

The HIV test result closest to the beginning of physical distancing period will be used as the participant's serological status at baseline. Follow-up will occur for a period of 12 months after baseline to observe the occurrence of HIV and STI infection, using information obtained from regular quarterly PrEP consultations. Based on the follow-up of the cohorts, the rate of responses to online questionnaires and retention is expected to be between $70 \%$ and $80 \%$.

\section{Sample size}

Sample size was calculated based on the number of participants enrolled in PrEP1519 and Combina cohorts, which corresponds to 891 and 731, respectively. Table 2 shows the profile of participants.

The MSM and TGW sample size for the COBra was estimated on the assumption of a maximum $6 \%$ reported behavioural changes (data on non-use of condoms, PEP or PrEP in the last sexual intercourse, in both cohorts) for both groups, during physical distancing period as compared with before, with power of $80 \%$ and a significance level of $95 \%$. It corresponds to 426 participants, with the assumption that the proportions of MSM and TGW do not change significantly in relation to the active participants in the cohorts.

\section{Data collection and study variables}

Data collection will include variables related to sociodemographic information, COVID-19, sexual health and mental health. These variables are detailed in figure 2 .

To prevent missing data, the study and data collection have been carefully planned. Only the essential information will be collected. We will use a friendly report form and will train all the researchers working on data collection.

A management team will be responsible for: verifying compliance with guidelines for research involving human subjects; assessing adherence to the study protocol; and confirming the quality and accuracy of the information collected and entered into the database. Reports will be done as close to real-time as possible during the course 
Table 2 Sociodemographic and sexual behaviour characteristics of PrEP1519 and Combina participants at baseline

\begin{tabular}{llllll}
\hline & \multicolumn{2}{l}{ PrEP 15-19 } & \multicolumn{2}{c}{ Combina } \\
\cline { 2 - 3 } \cline { 5 - 6 } Sociodemographics & $\mathbf{n}$ & \% & & $\mathbf{n}$ & \multicolumn{1}{c}{$\%$} \\
\hline Age (years) & 179 & 20,09 & & 0.3 \\
\hline $15-17$ & 712 & 79,91 & & 14 & 1.9 \\
\hline $18-19$ & - & - & 607 & 83.0 \\
$20-39$ & - & - & 108 & 14.8
\end{tabular}

Gender identity or sexual orientation

\begin{tabular}{lrrrr}
\hline MSM & 824 & 92,48 & 656 & 89.7 \\
\hline TGW & 67 & 7,52 & 75 & 10.3 \\
\hline Skin colour & & & & \\
\hline Black & 351 & 39,39 & 56 & 7.8 \\
\hline Pardo (brown) & 253 & 28,4 & 206 & 28.5 \\
\hline White & 255 & 28,62 & 447 & 61.9 \\
\hline Asian & 22 & 2,47 & 10 & 1.4 \\
\hline Indigenous & 10 & 1,12 & 3 & 0.4 \\
\hline Years of study & & & & \\
\hline$<8$ years & 28 & 3,14 & 15 & 2.1 \\
\hline$\geq 8$ years & 863 & 96,86 & 716 & 97.9 \\
\hline City & & & & \\
\hline Belo horizonte & 190 & 21,32 & - & - \\
\hline Curitiba & - & - & 26 & 3.6 \\
\hline Fortaleza & - & - & 67 & 9.2 \\
\hline Porto Alegre & - & - & 79 & 10.8 \\
\hline Ribeirão Preto & - & - & 44 & 6.0 \\
\hline Salvador & 288 & 32,32 & - & - \\
\hline São Paulo & 413 & 46,35 & 515 & 70.5 \\
\hline Sexual behaviour & & & & \\
\hline
\end{tabular}

Sexual behaviour

$\begin{array}{llrrr}\begin{array}{l}\text { Sex with casual } \\ \text { partner* }\end{array} & & & & \\ \text { No } & 228 & 29,61 & 59 & 8.1 \\ \text { Yes } & 542 & 70,39 & 672 & 91.9\end{array}$

Sex with stable partner

\begin{tabular}{lllll} 
No & 386 & 49,68 & 322 & 44.1 \\
Yes & 391 & 50,32 & 409 & 55.9 \\
\hline
\end{tabular}

*PrEP 15-19: in the last 3 months; Combina: in the last 6 months. MSM, men who have sex with men; PrEP, pre-exposure prophylaxis; TGW, transgender women.

of the study. Preliminary descriptive analyses will be conducted to evaluate frequency distributions and missingness. In case of missing data, study monitors will return to the questionnaires in order to complete the dataset. Remaining cases with missing data will be omitted and complete data analysis will be conducted.
Main outcomes

Three main outcomes will be analysed, namely HIV infection, STI and depressive symptoms:

- For HIV infection, rapid tests will be done as part of the quarterly follow-up routine of both cohorts by trained laboratory technicians. For the estimation of HIV prevalence, the laboratory diagnosis of HIV will follow the algorithm established by the MoH. ${ }^{59} \mathrm{~A}$ two HIV-RT methodology will be used for the detection of HIV antibodies 1 and 2. Preferably, a fourthgeneration test will be used as the first HIV-RT and a third-generation test as the second HIV-RT. In the samples with discordant reagent results, the Immunoblot test will be used. If the discrepancy persists, a new blood sample will be drawn to do a conventional laboratory test. For participants who cannot or chose not to attend PrEP consultations during physical distancing period, HIVST will be offered and delivered by mail. ${ }^{25} 60$

- STI diagnosis will be performed during clinical consultations, considering signs and symptoms. We will run quarterly treponemal and non-treponemal laboratory tests for syphilis on blood samples. Gonorrhoea and chlamydia will be investigating every 6 months using qualitative DNA detection through nucleic acid amplification test in urine samples in São Paulo, and research in the oropharynx, urethral and anorectal region in Salvador and Belo Horizonte.

- Finally, depressive symptoms will be investigated through the online questionnaires (baseline and sixth months after), using the Centre for Epidemiological Studies-Depression Scale, which is validate for both adults and adolescents.

\section{Data analysis}

Data obtained from questionnaires will be used to create indicators that will allow the categorisation of participants according to the dimensions of interest of the study, with emphasis on: degree of adherence to physical distancing measures, perception of COVID-19, and socioeconomic impact of the pandemic in daily life. Subsequently, we will evaluate the association of these COVID-19 indicators with study intermediate outcomes (interruption of use of HIV services, of HIV prevention methods and greater exposure to HIV) and major outcomes (HIV infection, STI and depression symptoms). This analysis will consider the different phases of the COVID-19 pandemic and control policies adopted. When pertinent, data previously collected during participants' follow-up will be used for comparison. Assessment of the effect of the public statements contrary to physical distancing measures will be stratified according to participants' opinion on the pandemic control measures. Stratification by age groups will also be carried out to analyse outcomes for adolescents and adults. 


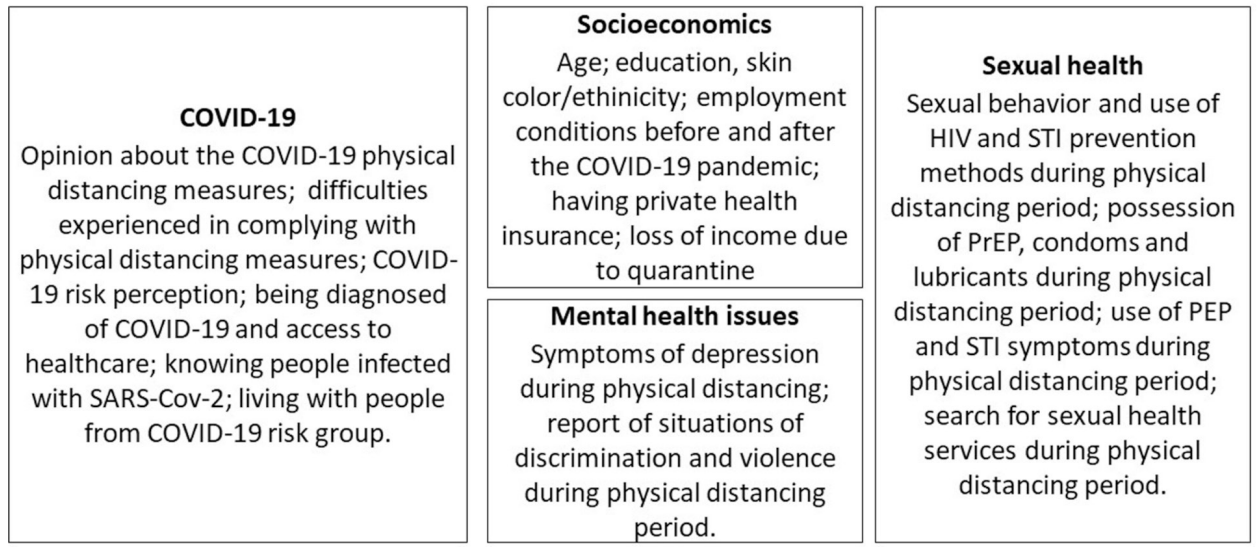

Figure 2 Variables to be explored in the online questionnaire at baseline and after 6 months at COBra (COVID Outbreak in Brazil) Study. PrEP, pre-exposure prophylaxis. STI, sexually transmitted infections.

\section{Statistical analysis}

Descriptive analysis will be carried out and frequency tables and figures will be produced to verify the distribution of the study variables. Measures of central tendency and variability will be calculated for the quantitative variables. Bivariate analysis will be carried out for the joint distribution of sociodemographic, socioeconomic, and sexual behaviour variables and outcome variables of interest.

Different regression models will be used to estimate associations between predictors and outcome variables, according to the different analytical strategies for the study outcomes. Therefore, OR, prevalence ratios and HRs will be estimated to investigate association between predictors and outcomes using, respectively, logistic, Poisson and Cox regression models.

Recognising the important differences existing between MSM and TGW, quantitative analyses will be carried out separately for each of these groups as much as possible. A lower participation of TGW in the study may compromise certain statistical analyses for this population, so we will apply analytical strategies specific to studies with small samples and will triangulate findings with the qualitative data.

\section{Qualitative design}

Procedures

A comprehensive approach ${ }^{61}$ using a mix of qualitative techniques will be adopted ${ }^{61-63}$ to enable a deep understanding of: (1) participants' social representations of the COVID-19 pandemic and their understandings of control measures, (2) participants' self-care practices during physical distancing period and (3) effects of the COVID-19 pandemic on HIV prevention behaviours.

\section{Data collection}

Techniques will include semistructured interviews, field work notes from researchers' diaries, and participants digital-based diaries.

PrEP1519 participants will be invited to chronicle their lives during physical distancing measures (June-August
2020) using digital-based diaries, a technique that can enhance participation ${ }^{64}$ and is adequate to investigate sensitive topics. ${ }^{65}$ These narratives will allow a longitudinal approach and a reduced recall bias. The diaries will be audio and written recorded, according to participants' choice. They will also be allowed to complement their reports with photographs that represent their lives during the pandemic. This can increase research participation by overcoming limitations related to limited literacy, and also because photographs are a cultural practice highly integrated in youths' participation in social networks. ${ }^{66} \mathrm{In}$ order to protect their confidentiality, pictures must not reveal their identity.

Interviews will be conducted by trained and experienced fieldwork researchers, through video calls or interactive voice response, according to participant's choice, to ensure their feasibility during physical distancing measures (September-November 2020). They will be audio recorded with participants' consent, and guided by a semistructured script (online supplemental appendix 1) covering the following themes, all relating to experiences during physical distancing measures: social representations of COVID-19; participants' self-care practices; sexual health and behaviour; mental health; and HIV prevention.

\section{Participants}

We will seek to include an equal number of TGW and MSM. For the interviews, we will invite at least 50 participants (25 TGW and 25 MSM) from the two cohorts in the sites of São Paulo and Salvador. For the diaries, at least 20 young MSM and TGW enrolled on PrEP1519 will be invited to participate, also from the two aforementioned cities.

\section{Data analysis}

Audiorecorded data from interviews and diaries will be transcribed verbatim for analysis. Lexicometric, thematic and phenomenological data analysis will be run independently and concurrently and will be triangulated for interpretation, as detailed below. TGW and MSM will be analysed separately. 


\section{Statistical textual analysis}

We will do a statistical textual analysis using IraMuTeQ. ${ }^{6768}$ This software converts textual data into numerical data to calculate the frequency of words and their relations ${ }^{69}$ and performs hierarchical clustering through correspondence factorial analysis. ${ }^{70}$ This allows identifying the underlying structure of the dataset and forming clusters ${ }^{71}$ based on the lexicon used by the interviewees to represent and communicate the phenomenon under analysis. Also, by adding variables that qualify the interviewees' speech (eg, age, sexual orientation, gender identity), the software allows the identification of particularities in the lexicon of different groups, making this technique particularly interesting to studying social representations. ${ }^{72}$ Additionally, the lexicometric analysis contributes to reducing the interference of the researchers' subjectivity in the categorisation of data. ${ }^{72}$

\section{Thematic analysis}

Data from interviews and diaries will also be subjected to iterative thematic analysis. ${ }^{73}$ We will use iterative categorisation to: systematically order and sort coded data, and to support the analysis by prioritising codes that will help identify reiteration, complementarity and discrepancy between codes. ${ }^{73}$

A codebook will be developed according to the following steps $^{74}$ : reading of transcriptions to ensure familiarisation with their content and stablish initial codes to raw data (inductive approach); development of new codes as additional themes emerge in the data (deductive approach) until code saturation is achieved; and labelling, description, definition and illustration of codes by raw data. Codes may be complemented with themes identified in the statistical textual analysis.

For coding visual data, a text log to describe the picture and the coded area will be systematically created. The analysis of this material will be guided by principles of phenomenological analysis of photographs. ${ }^{75}$

NVivo software will be used to assist coding and analytical processes, ${ }^{76}$ with the same codebook being applied to both textual and visual data. ${ }^{78}$

\section{Data Triangulation}

We will apply a systematic triangulation of perspectives, ${ }^{79}$ with triangulation being done across qualitative methods as well as with the quantitative data.

The integration of methods will occur during the interpretation stage by comparing findings to identify convergence, discrepancy and divergence ${ }^{80}$ for the following themes: sexual behaviour, HIV prevention, mental health and social representations of COVID-19.

By doing so, we recognise that the complexity of the issues under study requires a comprehensive approach, in which different methodologies-that express different epistemological positions-enable opportunities for either corroboration or identification of areas where deeper contextual analysis is required to address different levels and qualities of the social phenomena, ${ }^{78}$ thus creating new knowledge.

\section{DISCUSSION}

This study will seek to identify HIV prevention patterns, use of health services, mental health and self-care during the COVID-19 pandemic among youth and adult MSM and TGW. This will allow to assess the effects of the pandemic on the incidence of HIV, STI and depression among these groups and contribute to identifying factors associated with such effects. The convergent mixed-method approach will allow not only to measure these effects, but to build a more comprehensive understanding about them.

TGW and MSM may suffer a deeper impact from the COVID-19 pandemic when compared with the general population, and can be hard to reach. By building on existing HIV prevention cohorts, including the only PrEP demonstration study of adolescent MSM and TGW in Latin America (PrEP1519), we will be able to reach these populations in different Brazilian cities. This diversification of age groups and study sites will contribute for more consistent and comprehensive results.

The study results may contribute to the design of sexual and mental health policies that are better suited to TGW's and MSM's needs. Particularly, it may allow to identify strategies to ensure HIV prevention delivery, along with comprehensive sexual and mental healthcare, during situations of sanitary crisis, by combining telehealth with traditional service organisation. This will enable adaptations of service delivery in the involved cohorts and may contribute to adaptation of services in other contexts.

This study has limitations that need to be considered. First, our results may represent a more optimistic scenario than what would be found among the general population of TGW and MSM. Being included in demonstration studies-and, therefore, in health services-participants are likely to have a greater degree of information and more favourable social conditions than other MSM and TGW. Second, the use of internet-based data collection techniques may impede the participation of those who have precarious or no internet access, and who may be precisely the most vulnerable to the harmful effects of the COVID-19 pandemic. Third, the depth of qualitative data may be impaired by the challenges inherent in remote data collection, such as not being aware of participants' facial expressions and body language. Finally, certain statistical analysis regarding TGW may have limited validity, given potential difficulties to recruit this group.

\section{ETHICS AND DISSEMINATION}

PrEP1519 and Combina were approved by the Ethics Research Committee (ERC) from the Universities coordinating the studies. Combina was also approved by the Brazilian National Ethics Research Commission (CONEP) and PrEP15-9 by the WHO's ERC. For COBra study, a notification of substantial amendments was submitted to and approved by all the ERCs that had previously approved PrEP15-19 and Combina. 
Results will be published in peer-reviewed journals and presented at scientific meetings, assuring transparency of data and anonymity of participants. Complementarily, informative flyers will be elaborated to communicate the study findings to participants, to key stakeholders (MoH, local health authorities, PrEP1519 and Combina staff), aiming to inform how services can better respond to the needs of participants during a sanitary crisis. This material will also be made available at the PrEP1519 and Combina websites.

\section{PATIENT AND PUBLIC INVOLVEMENT}

This study is strongly oriented by lessons learnt from patients during the implementation of PrEP1519 and Combina. Access to sexual and mental healthcare have been shown to be a central need among participants, and assuring access and continuity of care has often been challenging.

Patients were not directly involved in the design of the COBra protocol because it was developed during the COVID-19 crisis, with time constrains and physical distancing measures preventing a wider community involvement. It is worth noticing, though, that PrEP1519 has a strong community participation, with youth TGW and MSM working directly in recruitment and retainment activities.

To assure dissemination of findings to participants and communities, we will develop informative flyers with voluntary participants, to be made available in all the channels used by the research teams to communicate with participants (eg, cohorts' websites, WhatsApp groups and Instagram).

\section{Author affiliations}

${ }^{1}$ Escola FIOCRUZ de Governo, FIOCRUZ Brasília, Fundação 0swaldo Cruz, Brasília, DF, Brazil

${ }^{2}$ Groupe de Recherche en Psychologie Sociale (EA 4163), Université Lumière Lyon 2 - Campus Porte des Alpes, Bron, France

${ }^{3}$ Instituto de Saúde Coletiva (ISC), Universidade Federal da Bahia, Salvador, BA, Brazil

${ }^{4}$ Programa de Pós-Graduação em Saúde Coletiva, Universidade Catolica de Santos, Santos, SP, Brazil

${ }^{5}$ Departamento de Ciências da Vida, Universidade do Estado da Bahia, Salvador, BA, Brazil

${ }^{6}$ Departamento de Medicina Preventiva, Universidade de Sao Paulo Faculdade de Medicina, Sao Paulo, São Paulo, Brazil

${ }^{7}$ Institute on Inequalities in Global Health, University of Southern California, Los Angeles, California, USA

${ }^{8}$ Departamento de Doenças Infecciosas e Medicina Tropical, Faculdade de Medicina, Universidade Federal de Minas Gerais, Belo Horizonte, MG, Brazil

\section{Twitter Laio Magno @laiomagno}

Acknowledgements The authors would like to acknowledge the researchers working in the implementation of this study: Dirceu Greco, Érica Dumont, Éricles Rufino, Fabiane Soares, Fernanda Soares, Ivo Patrick, Luiz Fábio Alves de Deus, Paola Souza, Paula Massa, Priscilla Caires, Samuel Gomes da Silva, Thaís Fonseca, Thaís Aranha, Thiago Sabino, Unaí Tupinambás e Wilver Portella.

Contributors DF, ID, EMZ, XM, LM, ADG and MP conceived and designed the COBra Study protocol. MTC and LF participated in the design of the study, particularly in the development of the qualitative investigation. MW and LAdS collaborated on the design of the quantitative investigation. All authors worked on the drafting of this manuscript with relevant intellectual contributions.

Funding COBra is supported by the ANRS - Maladies infectieuses émergentes, grant number ANRS COV 31 COBra. PrEP1519 is funded by UNITAID (grant number 2017-15-FIOTECPrEP), SVS-MS/CNPq (404055/2018-4) and the Brazilian Ministry of Health. Combina is funded by the Brazilian Ministry of Health and the Pan American Health Organization (PAHO).

Competing interests None declared.

Patient consent for publication Not required.

Provenance and peer review Not commissioned; externally peer reviewed.

Supplemental material This content has been supplied by the author(s). It has not been vetted by BMJ Publishing Group Limited (BMJ) and may not have been peer-reviewed. Any opinions or recommendations discussed are solely those of the author(s) and are not endorsed by BMJ. BMJ disclaims all liability and responsibility arising from any reliance placed on the content. Where the content includes any translated material, BMJ does not warrant the accuracy and reliability of the translations (including but not limited to local regulations, clinical guidelines, terminology, drug names and drug dosages), and is not responsible for any error and/or omissions arising from translation and adaptation or otherwise.

Open access This is an open access article distributed in accordance with the Creative Commons Attribution Non Commercial (CC BY-NC 4.0) license, which permits others to distribute, remix, adapt, build upon this work non-commercially, and license their derivative works on different terms, provided the original work is properly cited, appropriate credit is given, any changes made indicated, and the use is non-commercial. See: http://creativecommons.org/licenses/by-nc/4.0/.

\section{ORCID iDs}

Dulce Ferraz http://orcid.org/0000-0002-0443-3183

Xavier Mabire http://orcid.org/0000-0001-9058-0085

Laio Magno http://orcid.org/0000-0003-3752-0782

\section{REFERENCES}

1 WHO Director-General's opening remarks at the media briefing on COVID-19 - 11 March 2020. Available: https://www.who.int/dg/ speeches/detail/who-director-general-s-opening-remarks-at-themedia-briefing-on-covid-19-11-march-2020

2 How to stop COVID-19 fuelling a resurgence of AIDS, malaria and tuberculosis. Nature 2020;584:169.

3 Hussein J. COVID-19: what implications for sexual and reproductive health and rights globally? Sex Reprod Health Matters 2020;28:1746065. doi:10.1080/26410397.2020.1746065

4 Aminnejad R, Alikhani R. Physical distancing or social distancing: that is the question. Can J Anesth 2020;67:1457-8. doi:10.1007/ s12630-020-01697-2

5 Brooks SK, Webster RK, Smith LE, et al. The psychological impact of quarantine and how to reduce it: rapid review of the evidence. Lancet 2020;395:912-20.

6 Portal de Notícias G1. Casos de coronavírus no Brasil em 8 de abril, 2020. Available: https://g1.globo.com/bemestar/coronavirus/noticia/ 2020/04/08/casos-de-coronavirus-no-brasil-em-8-de-abril.ghtml

7 Portal do Ministério da Saúde do Brasil. Ministério da Saúde declara transmissão comunitária nacional, 2020. Available: https://www. saude.gov.br/noticias/agencia-saude/46568-ministerio-da-saudedeclara-transmissao-comunitaria-nacional

8 CoVida R. Painel Coronavírus Brasil, 2020. Available: http://painel. covid19br.org/\#

9 Worldometers. Countries where coronavirus has spread, 2020. Available: https://www.worldometers.info/coronavirus/countrieswhere-coronavirus-has-spread/

10 Ortega F, Orsini M. Governing COVID-19 without government in Brazil: ignorance, neoliberal authoritarianism, and the collapse of public health leadership. Glob Public Health 2020;15:1257-77. doi:10 .1080/17441692.2020.1795223

11 Aquino EML, Silveira IH, Pescarini JM, et al. Medidas de distanciamento social no controle da pandemia de COVID-19: potenciais impactos e desafios no Brasil. Ciênc. saúde coletiva 2020;25:2423-46. doi:10.1590/1413-81232020256.1.10502020

12 Bish A, Michie S. Demographic and attitudinal determinants of protective behaviours during a pandemic: a review. $\mathrm{Br} \mathrm{J}$ Health Psychol 2010;15:797-824.

13 Fundação Instituto Brasileiro de Geografia e Estatística (IBGE). Síntese de indicadores sociais: uma análise das condiçõoes de vida da populaçãao brasileira. Rio de Janeiro ibge; 2018. 
14 Musso D, Ko Al, Baud D. Zika Virus Infection - After the Pandemic. N Engl J Med 2019;381:1444-57.

15 Wenham C, Smith J, Morgan R, et al. COVID-19: the gendered impacts of the outbreak. Lancet 2020;395:846-8. doi:10.1016/ S0140-6736(20)30526-2

16 Alpalhão M, Filipe P. The impacts of isolation measures against SARS-CoV-2 infection on sexual health. AIDS Behav 2020;24:2258-9. doi:10.1007/s10461-020-02853-x

17 Ahmed Z, Sonfield A. The COVID-19 outbreak: potential fallout for sexual and reproductive health and rights. Guttmacher Inst 2020.

$18 \mathrm{Li} \mathrm{G}$, Tang D, Song B, et al. Impact of the COVID-19 pandemic on partner relationships and sexual and reproductive health: crosssectional, online survey study. J Med Internet Res 2020;22:e20961.

19 Hogan AB, Jewell BL, Sherrard-Smith E, et al. Potential impact of the COVID-19 pandemic on HIV, tuberculosis, and malaria in low-income and middle-income countries: a modelling study. Lancet Glob Health 2020;8:e1132-41.

20 Jewell BL, Mudimu E, Stover J, et al. Potential effects of disruption to HIV programmes in sub-Saharan Africa caused by COVID-19: results from multiple mathematical models. Lancet HIV 2020;7:e629-40. doi:10.1016/S2352-3018(20)30211-3

21 Ministério da Saúde (BR). Ofício circular no 8/2020/CGAHV/.DCCI/ SVS/MS | Departamento de Doenças de Condições Crônicas E Infecções Sexualmente Transmissíveis, 2020. Available: http ://www. aids.gov.br/pt-br/legislacao/oficio-circular-no-82020cgahvdccisvsms

22 RNP+Brasil. Pesquisa ICPCOVID com PVHA entra em nova fase, 2020. Available: http ://www.rnpvha.org.br/pesquisa-icpcovid-compvha-entra-em-nova-fase.html

23 Pinto RM, Park S. COVID-19 pandemic disrupts HIV continuum of care and prevention: implications for research and practice concerning community-based organizations and frontline providers. AIDS Behav 2020;24:2486-9. doi:10.1007/s10461-020-02893-3

24 Hoagland B, Torres TS, Bezerra DRB, et al. Telemedicine as a tool for PrEP delivery during the COVID-19 pandemic in a large HIV prevention service in Rio de Janeiro-Brazil. Brazilian J Infect Dis 2020;24:360-4. doi:10.1016/j.bjid.2020.05.004

25 Dourado I, Magno L, Soares F, et al. Adapting to the COVID-19 pandemic: continuing HIV prevention services for adolescents through Telemonitoring, Brazil. AIDS Behav 2020;24:1994-9. doi:10.1007/s10461-020-02927-w

26 Bastos FI, Bastos LS, Coutinho C, et al. HIV, HCV, HBV, and syphilis among transgender women from Brazil: assessing different methods to adjust infection rates of a hard-to-reach, sparse population. Medicine 2018;97:S16-24.

27 Kerr L, Kendall C, Guimarães MDC, et al. HIV prevalence among men who have sex with men in Brazil: results of the 2nd national survey using respondent-driven sampling. Medicine 2018;97:S9-15.

28 Ferraz D, Couto MT, Zucchi EM, et al. AIDS-and sexuality-related stigmas underlying the use of post-exposure prophylaxis for HIV in Brazil: findings from a multicentric study. Sex Reprod Heal matters 2019;27:107-21.

29 Santos G-M, Ackerman B, Rao A, et al. Economic, mental health, HIV prevention and HIV treatment impacts of COVID-19 and the COVID-19 response on a global sample of Cisgender gay men and other men who have sex with men. AIDS Behav 2021;25:311-21. doi:10.1007/s10461-020-02969-0

30 Sanchez TH, Zlotorzynska M, Rai M, et al. Characterizing the impact of COVID-19 on men who have sex with men across the United States in April, 2020. AIDS Behav 2020;24:2024-32.

31 Torres TS, Hoagland B, Bezerra DRB, et al. Impact of COVID-19 pandemic on sexual minority populations in Brazil: an analysis of Social/Racial disparities in maintaining social distancing and a description of sexual behavior. AIDS Behav 2021;25:73-84. doi:10.1007/s10461-020-02984-1

32 Döring N. How is the COVID-19 pandemic affecting our Sexualities? An overview of the current media narratives and research hypotheses. Arch Sex Behav 2020;49:2765-78. doi:10.1007/s10508020-01790-z

33 Chow EPF, Hocking JS, Ong JJ, et al. Changing the use of HIV preexposure prophylaxis among men who have sex with men during the COVID-19 pandemic in Melbourne, Australia. Open Forum Infect Dis 2020;7:ofaa275. doi:10.1093/ofid/ofaa275

34 Sharma A, Pillai DR, Lu M, et al. Impact of isolation precautions on quality of life: a meta-analysis. J Hosp Infect 2020;105:35-42.

35 Barratt RL, Shaban R, Moyle W. Patient experience of source isolation: lessons for clinical practice. Contemp Nurse 2011;39:180-93.

36 Vizard T, Davis J, White E. Coronavirus and depression in adults, Great Britain: June 2020 Office for National Statistics; 2020. https:// www.ons.gov.uk/peoplepopulationandcommunity/wellbeing/articles/ coronavirusanddepressioninadultsgreatbritain/june2020?fbclid=
IwAR3_1Fd-GqGchHtqj0c1FP01OXsA18cwptWv3SXN1rtsoUcq93rZ 8Lb0JkM [Accessed 18 Sep 2020].

37 Czeisler Mark É, Lane RI, Petrosky E, et al. Mental Health, Substance Use, and Suicidal Ideation During the COVID-19 Pandemic United States, June 24-30, 2020. MMWR Morb Mortal Wkly Rep 2020;69:1049-57.

38 World Health Organization (WHO). WHO consolidated guideline on self-care interventions for health: sexual and reproductive health and rights: executive summary 2019.

39 Frost DM, Meyer IH, Schwartz S. Social support networks among diverse sexual minority populations. Am J Orthopsychiatry 2016:86:91-102. doi:10.1037/ort0000117

40 Schulman S. Familial homophobia: os experience in search of recognition. Ties that Bind Fam homophobia its consequences 2009:1-17.

41 Duarte A de S, Cymbalista R. A Casa 1: habitação E diálogo entre público $\mathrm{E}$ privado $\mathrm{Na}$ acolhida de jovens LGBT. Encontro da Assoc Nac Pesqui e Pós-Graduação em Arquitetura e Urban 2018;5:8527-44.

42 Moscovici S. Social representations: explorations in social psychology. New York: NYU Press, 2000.

43 Kalampalikis N, Apostolidis T. Social representations. In: Lo Monaco G, Delouvée S, Rateau P, eds. Theories, methods and applications, 2016: 69-77.

44 Apostolodis T. Social representations and triangulation: an application in social psychology of health. Psicol Teor e Pesqui 2006;22:211-27.

45 Apostolidis T, Dany L. Représentations sociales et risques sanitaires : perspectives sociocognitives. Tempus - Actas Saúde Coletiva 2012;6:35-50.

46 Jodelet D. Représentations Sociales et Mondes de Vie. Archives contemporaines 2015;1.

47 Johnson RB, Onwuegbuzie AJ, Turner LA. Toward a definition of mixed methods research. $J$ Mix Methods Res 2007;1:112-33. doi:10.1177/1558689806298224

48 Grangeiro A, Couto MT, Peres MF, et al. Pre-Exposure and postexposure prophylaxes and the combination HIV prevention methods (the combine! study): protocol for a pragmatic clinical trial at public healthcare clinics in Brazil. BMJ Open 2015;5:e009021-11.

49 WHO. Sexual health, human rights and the law. Geneva, Switzerland World Health Organization; 2015.

50 Ferguson L, Fried S, Matsaseng T, et al. Human rights and legal dimensions of self care interventions for sexual and reproductive health. BMJ 2019;365:I1941. doi:10.1136/bmj.I1941

51 Ayres JR, Paiva V, França I. From Natural History of Disease to Vulnerability. In: Routledge Handbook of global public health. Routledge, 2015: 98-107.

52 Morin M, Terrade F, Préau M. Psychologie communautaire et psychologie de la santé : l'implication de la recherche psychosociale dans la promotion de la santé. Psychol Fr 2012;57:111-8.

53 Wagner W, Kronberger N, Seifert F. Collective symbolic coping with new technology: knowledge, images and public discourse. Br J Soc Psychol 2002;41:323-43.

54 Morin M. Parcours de santé. Armand Colin 2004.

55 Wagner W, Hayes N. Everyday discourse and common sense: the theory of social representations. Palgrave Macmillan, 2005.

56 Testa RJ, Habarth J, Peta J, et al. Development of the gender minority stress and resilience measure. Psychol Sex Orientat Gend Divers 2015;2:65-77. doi:10.1037/sgd0000081

57 Meyer IH. Minority stress and mental health in gay men. $J$ Health Soc Behav 1995;36:38-56. doi:10.2307/2137286

58 Richards K, Campenni C, Muse-Burke J. Self-Care and well-being in mental health professionals: the mediating effects of Self-awareness and mindfulness. J Ment Heal Couns 2010;32:247-64. doi:10.17744/ mehc.32.3.0n31v88304423806

59 Ministério da Saúde (BR). Manual Técnico para o Diagnóstico da Infecção pelo HIV em Adultos e Crianças. Secr Vigilância em Saúde, Dep Vigilância, Prevenção e control das Infecções sex Transm do HIV/AIDS e das Hepatites Virais - Brasília Ministério da Saúde; 2016.

60 PrEPara Salvador \#vemdeprep. O babado do autoteste!!! 2019. Available: https://www.youtube.com/watch?v=iYCuQ09Cu6w\&t

61 Santiago-Delefosse M, Carral MDR. Les méthodes qualitatives os psychologie et sciences humaines de la santé Dunod; 2017.

62 Minayo MCdeS. Análise qualitativa: teoria, passos E fidedignidade. Ciênc. saúde coletiva 2012;17:621-6. doi:10.1590/S141381232012000300007

63 Malterud K. Qualitative research: Standards, challenges, and guidelines. The Lancet 2001;358:483-8. doi:10.1016/S01406736(01)05627-6 
64 Darbyshire P, MacDougall C, Schiller W. Multiple methods in qualitative research with children: more insight or just more? Qual Res 2005;5:417-36. doi:10.1177/1468794105056921

65 Baer A, Saroiu S, Koutsky LA. Obtaining sensitive data through the web: an example of design and methods. Epidemiology 2002;13:640-5.

66 Davis K, Minckas N, Bond V, et al. Beyond interviews and focus groups: a framework for integrating innovative qualitative methods into randomised controlled trials of complex public health interventions. Trials 2019;20:329.

67 Ratinaud P, Marchand P. Des mondes lexicaux aux représentations sociales. Une première approche des thématiques dans les débats à l'Assemblée nationale (1998-2014). Mots 2015:57-77.

68 Marty E, Marchand P, Ratinaud P. Les médias et l'opinion- Eléments théoriques et méthodologiques pour une analyse Du débat sur l'identité nationale. Bulletin of Sociological Methodology/Bulletin de Méthodologie Sociologique 2013;117:46-60.

69 Leblanc J-M. Proposition de protocole pour l'analyse des données textuelles : pour une démarche expérimentale en lexicométrie. Nouv Perspect en Sci Soc 2016;11:25-63.

70 Marpsat M. La méthode Alceste. Sociologie2010.

71 Ratinaud P. Amélioration de la précision et de la vitesse de l'algorithme de classification de la méthode Reinert dans IRaMuTeQ.
Proceedings of the 14th international conference on statistical analysis of textual data, 2018:616-25.

72 Grenon V, Larose F, Carignan I. Réflexions méthodologiques sur l'étude des représentations sociales : rétrospectives de recherches antérieures. Phronesis 2013;2:43-9.

73 Neale J. Iterative categorization (IC): a systematic technique for analysing qualitative data. Addiction 2016;111:1096-106.

74 Roberts K, Dowell A, Nie J-B. Attempting rigour and replicability in thematic analysis of qualitative research data; a case study of codebook development. BMC Med Res Methodol 2019;19:66.

75 Ziller RC, Smith DE. A phenomenological utilization of Photographs. J Phenomenol Psychol 1977;7:172.

76 Bazeley P, Jackson K. Qualitative data analysis with NVivo. SAGE publications limited, 2013.

77 Gibbs GR. Qualitative data analysis: explorations with NVivo. Open University, 2002.

78 Lewis RB. NVivo 2.0 and ATLAS.ti 5.0: a comparative review of two popular qualitative Data-Analysis programs. Field methods 2004;16:439-64.

79 Flick U. Triangulation. In: Denzin NK, Lincoln YS, eds. The SAGE Handbook of qualitative research. sage, 2017: 444-61.

80 Steinmetz-Wood M, Pluye P, Ross NA. The planning and reporting of mixed methods studies on the built environment and health. Prev Med 2019;126:105752. 